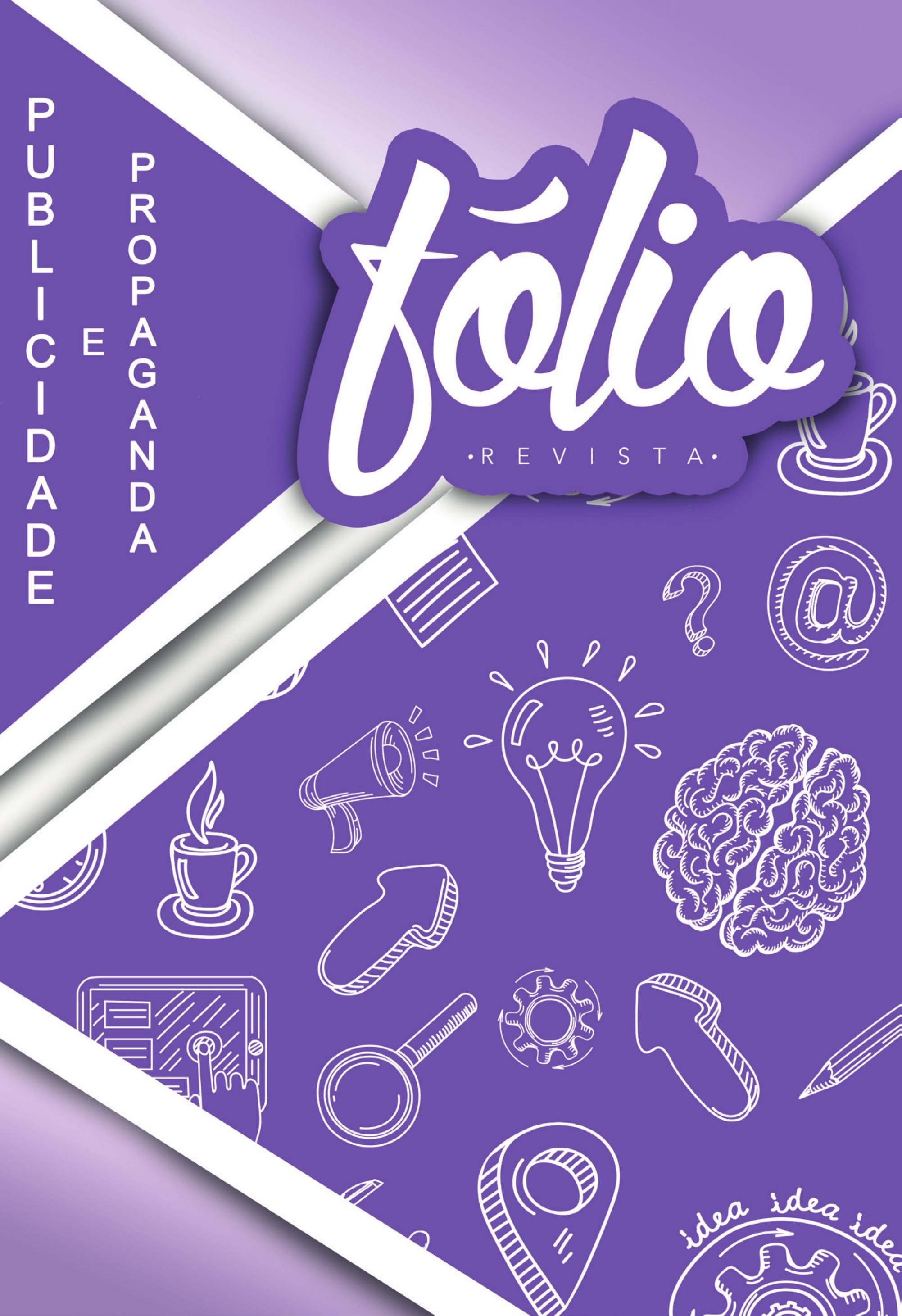




\title{
A percepção da marca Pepsi, a partir do seu posicionamento, entre jovens da região metropolitana de Porto Alegre
}

\author{
The perception of the Pepsi brand, from its \\ positioning, among youngs of the metropolitan \\ region of Porto Alegre
}

\author{
Mariana Bestroinski ${ }^{1}$ \\ Maristela de Oliveira Franco²

\section{Resumo}

O mercado de refrigerantes está perdendo espaço no Brasil por conta da mudança de hábito dos brasileiros ao optarem por outras categorias de bebidas. Tendo isso em vista, o assunto abordado neste estudo é a percepção da marca Pepsi, a partir do seu posicionamento perante o público jovem de Porto Alegre e Região Metropolitana. Como consequência. Considerando esse contexto, esta pesquisa busca responder à seguinte questão: qual a percepção dos jovens em relação à Pepsi a partir do posicionamento da marca? Para isso, este estudo descritivo quantitativo utilizou-se da técnica de coleta de dados, da pesquisa bibliográfica, da pesquisa documental e da aplicação de questionário. Para analisar os dados, usou-se a análise de conteúdo categorial. Dessa maneira, o estudo indicou que a percepção dos jovens em relação a Pepsi é bastante positiva e que essa marca de refrigerante não vende somente o produto, mas sim um estilo de comportamento.

Palavras-chave: Pepsi. Jovens. Marca. Posicionamento.

\section{Abstract}

The soft drink market is losing ground in Brazil because of the change of habit of Brazilians when opting for other categories of beverages. With this in view, the subject of this study is the perception of the Pepsi brand, from its positioning before the young public of Porto Alegre and Metropolitan Region. Considering this context, this research seeks to answer the following question: what is the perception of the young people regarding Pepsi from the positioning of the brand? For this, this quantitative descriptive study was used the technique of data collection, bibliographic research, documentary research and questionnaire application. To analyze the data, we used categorical content analysis. Thus, the study indicated that the perception of young people in relation to Pepsi is quite positive and that this brand of soft drink not only sells the product, but a style of behavior.

Keywords: Pepsi.Young.Brand.Positioning.

\footnotetext{
1 Publicitária graduada em Publicidade e Propaganda pelo Centro Universitário Metodista, de Porto Alegre. E-mail para contato: bestroinski. mariana@gmail.com

2 Professora mestre do curso de Publicidade e Propaganda, Jornalismo e Administração do Centro Universitário Metodista - IPA
} 


\section{Introdução}

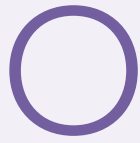
trabalho trata sobre o tema da percepção da marca de refrigerante Pepsi entre jovens. A marca Pepsi, segundo o site Mundo das Marcas ${ }^{3}$, é considerada uma forte concorrente da Coca-Cola e busca consumidores na nova geração além de ser um dos ícones mais reconhecidos no mercado financeiro global.

Em relação ao consumo de refrigerantes, o site da Nielsen ${ }^{4}$ registra uma mudança de comportamento quanto ao público consumidor, que vem trocando marcas tradicionais por marcas mais acessíveis. Assim, as grandes marcas de refrigerante estão fazendo promoções a fim de atrair os consumidores novamente. O comportamento de consumo dos jovens, de idade entre 18 e 24 anos, o site Exame ${ }^{5}$ mostra que eles possuem comportamento de consumo moderado, e a preferência pela busca de informação está voltada para as redes sociais.

A delimitação do tema da pesquisa é a percepção da marca Pepsi entre jovens de 18 a 24 anos na Região Metropolitana de Porto Alegre. Foi realizada uma pesquisa quantitativa, com uma amostra não probabilística, por conveniência, com a aplicação de um questionário online para 110 jovens de ambos os gêneros, moradores da Região Metropolitana de Porto Alegre, na faixa etária de 18 a 24 anos no segundo semestre de 2017. O Rio Grande do Sul foi o único lugar do mundo em que o refrigerante Pepsi ganhou a chamada "Guerra das Colas", uma disputa entre as empresas The Coca-Cola Company e PepsiCo pelo primeiro lugar em vendas, de acordo com o site Mundo das Marcas 6 .

Para maior compreensão da pesquisa, foi uti-

3 Disponível em: <http://mundodasmarcas.blogspot.com. br/2006/05/pepsi-cola-next-generation.html>. Acesso em: 15 mar. 2017.

4 Disponível em: <http://www.nielsen.com/br/pt/insights/ news/2016/4-fatores-essenciais-que-movem-o-mercado-debebidas.html>. Acesso em: 16 mar. 2017.

5 Disponível em: <http://exame.abril.com.br/marketing/10-fatossobre-o-comportamento-dos-jovens-brasileiros/>. Acesso em: 15 mar. 2017.

6 Disponível em: < http://mundodasmarcas.blogspot.com. br/2006/05/pepsi-cola-next-generation.html >. Acesso em: 15 mar. 2017. lizada a análise de conteúdo categorial que possibilitou atingir os objetivos deste estudo.

Conforme o site $\mathrm{G}^{7}$, somente $30 \%$ dos jovens brasileiros, entre 18 e 24 anos, consome refrigerante diariamente. $\bigcirc$ site da $\mathrm{Abir}^{8}$ aponta que caíram a produção e o consumo de refrigerantes nos últimos anos. Pelo fato da Pepsi um dia já tenha sido campeã em vendas no estado do Rio Grande do Sul, e observando o comportamento do público jovem, esta pesquisa propõe o seguinte questionamento: qual a percepção dos jovens em relação à Pepsi a partir do posicionamento da marca?

O objetivo geral da pesquisa é verificar a percepção dos jovens em relação à Pepsi, a partir do posicionamento da marca. E os objetivos específicos são analisar quais ações da Pepsi impactaram e geraram mais engajamento dos jovens moradores da Região Metropolitana de Porto Alegre com a marca. E avaliar o nível de empatia da marca Pepsi com o público jovem morador da Região Metropolitana de Porto Alegre.

A justificativa da pesquisa ocorre devida a importância do trabalho sobre a Pepsi ter sua pertinência por ser considerada uma marca voltada ao público jovem. Portanto, é necessária a realização de estudos que explorem os conteúdos relevantes sobre esse segmento na atualidade.

\section{Marketing}

Segundo Kotler e Armstrong (2015), marketing é a situação que ocorre quando se estabelece uma troca de valor entre as pessoas e as empresas, a fim de atender às suas necessidades e aos seus desejos. Para Kotler e Keller (2013), o marketing abrange a identificação e a satisfação das necessidades humanas e sociais que estabelecem uma troca, é a escolha do mercado alvo, da capacitação e da fidelização através da entrega e da comunicação com o cliente. Kotler e Armstrong

\footnotetext{
7 Disponível em: <http://g1.globo.com/bemestar/noticia/2016/04/ estudo-aponta-que-30-dos-jovens-do-brasil-tomam-refrigerantediariamente.html>. Acesso em: 17 mar. 2017.
}

8 Disponível em: <http://abir.org.br/o-setor/dados/>. Acesso em: 22 mar. 2017. 
(2015) apontam que os profissionais de marketing precisam ter cuidado ao definir o nível de expectativas, porque o valor e a satisfação para o cliente são elementos fundamentais para desenvolver as relações com o público.

\section{Marketing 3.0}

Kotler, Kartjaya e Setianwan (2010) explicam que o Marketing 3.0 é voltado para os valores, a fim de tornar o mundo um lugar melhor. Sua força está voltada para as novas tecnologias. As empresas veem o público consumidor como seres humanos plenos, e o conceito de marketing é direcionado para os valores. As empresas trabalham com missão, visão e valores, e sua proposta de valor torna-se, além de funcional e emocional, agora também espiritual. $\bigcirc$ Marketing 3.0 pode ser considerado como a era do marketing colaborativo em que as pessoas criam e consomem notícias, pensamentos e diversão, transformando-se não somente em consumidores. As mídias sociais tornam-se cada vez mais importantes, porque os consumidores influenciam outros consumidores devido à sua expressividade ao exporem opiniões e experiências.

\section{Marketing global}

Cateora e Graham (2009) afirmam que o marketing internacional é a atuação do mercado empresarial, direcionada para determinar preços, promover e orientar a produção de produtos e de serviços de uma empresa para seus clientes, abrangendo outros países. Os fundamentos de marketing são universalmente aplicados; contudo, é preciso conhecer as restrições legais, o controle do governo, o clima do país etc. É importante, para o profissional de marketing, estudar as variáveis de cada país antes de elaborar um projeto de marketing. Pigozzo (2013) aponta que o mercado global é aquele em que se consegue comunicar a mesma mensagem, o mesmo apelo de marketing e o mesmo produto (estrutura, receita, design), partindo da decisão de escolha para diferentes mercados.

\section{Marca e branding}

Solomon (2011) explica que a personalidade da marca é um conjunto de características (valor) que os consumidores agregam ao produto como se fosse uma pessoa. Para obter sucesso com a personalidade da marca, é fundamental construir junto ao consumidor uma fidelidade. Kotler e Keller (2013) definem branding como um meio de distinguir produtos de uma empresa em relação a outros. A função do branding é elaborar estruturas para auxiliar o consumidor a organizar o conhecimento em relação aos produtos a fim de tomar a decisão mais objetiva e gerar valor para a empresa. Para Oliveira (2015), o conceito de brand love é novo no mercado, está em construção, mas tem demonstrado ser de longo prazo, pois é causado pela influência e pela relevância do marketing e de suas variáveis em relação à fidelidade da marca.

\section{Posicionamento}

Aaker (2007) ressalta que a posição estratégica que diferencie, de fato, o produto de seus concorrentes é repercutir junto ao cliente a eficiência da comunicação e sua consistência em longo prazo. A posição estratégica de uma empresa é a sua identidade para a marca. A posição estratégica pode afetar de maneira drástica os clientes em potencial. Ries e Trout (2009) indicam que, para obter um posicionamento exclusivo, precisa-se ignorar o convencional, encontrar um conceito fora do produto e olhar dentro da mente do consumidor. Um bom posicionamento requer perseverança, tempo e manutenção ano após ano. Para obter-se sucesso, não se pode esquecer-se do posicionamento do concorrente nem se afastar da sua própria posição.

\section{Comportamento do consumidor}

Kotler e Keller (2013) apontam que o profissional de marketing precisa entender o consumidor, entender o comportamento de compra que é 
influenciado por fatores diversos, como culturais, sociais, pessoais e psicológicos. Solomon (2011) exprime que o consumidor é envolvido por meio da importância do produto/serviço ou da marca. O envolvimento é construído socialmente e deriva de diversos fatores.

\section{Procedimentos metodológicos}

Neste trabalho, optou-se por uma pesquisa no âmbito do receptor, de caráter descritivo e de natureza quantitativa. A delimitação da pesquisa foi determinada com uma amostra não-probabilística, com a realização de uma pesquisa quantitativa. A técnica e os instrumentos de coleta de dados escolhidos para a realização da pesquisa foram: pesquisa bibliográfica, documental e aplicação de questionário. A técnica de análise de dados escolhida pela pesquisadora foi a de análise de conteúdo categorial.

De acordo com Malhotra (2005), a pesquisa descritiva é utilizada como uma ferramenta para o papel da pesquisa conclusiva, que tem como seu principal objetivo descrever algo ou alguma coisa. Em relação a procedimento quantitativo. Malhotra (2005), explica que exerce a função de quantificar os dados, buscando evidências de cunho conclusivo, baseado em grandes amostras representadas e aplicadas a uma análise estatística

A delimitação da pesquisa é composta por uma amostra não probabilística com a aplicação de um questionário para 110 pessoas de ambos os sexos, na faixa etária de 18 a 24 anos, moradores da cidade de Porto Alegre e de sua região metropolitana, no estado do Rio Grande do Sul. A pesquisa foi aplicada no período de 8 a 21 de setembro de 2017.

Segundo Levine (2008), em uma amostra não probabilística, o pesquisador seleciona os itens ou os indivíduos sem conhecer suas respectivas probabilidades de seleção. Para Malhotra (2005), a amostra não probabilística depende do julgamento pessoal do pesquisador com base na conveniência, pois não há como avaliar a precisão exata dos resultados.

Para a pesquisa foi adotada a análise de con- teúdo categorial.No qual foram utilizadas três categorias para a análise, sendo elas: 1) nível de percepção em relação à marca; 2) nível de engajamento com a marca; e 3) participação em eventos.

\section{Análise dos resultados}

Nesta etapa do trabalho, serão apresentados os dados coletados das respostas dos participantes do questionário, acompanhado da análise de conteúdo categorial.

O questionário online foi aplicado entre os dias 8 e 21 de setembro de 2017, na plataforma Google Docs. Utilizou-se o roteiro de questões como guia para orientar os participantes. Nesta pesquisa participaram 110 respondentes de ambos os gêneros, que residem em Porto Alegre e Região Metropolitana, com idade entre 18 a 24 anos e que consomem ou não refrigerante da marca Pepsi.

Gráfico 1 - Gênero dos entrevistados

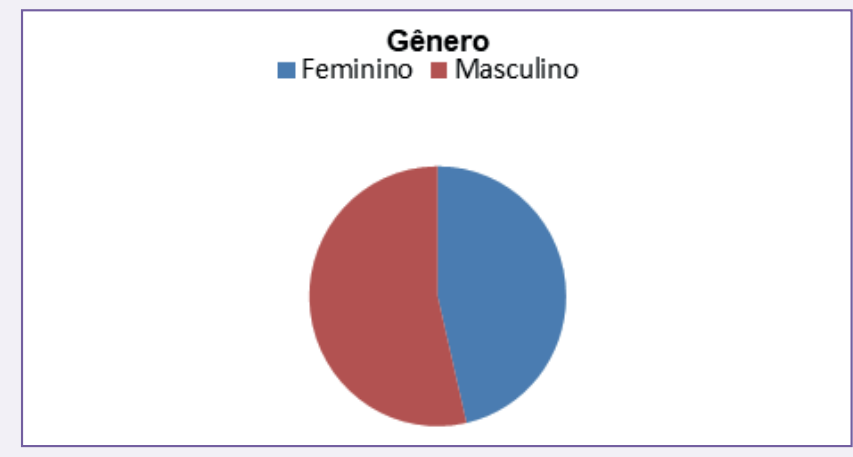

Fonte: Elaborado pela pesquisadora

Gráfico 2 - Faixa etária dos entrevistados

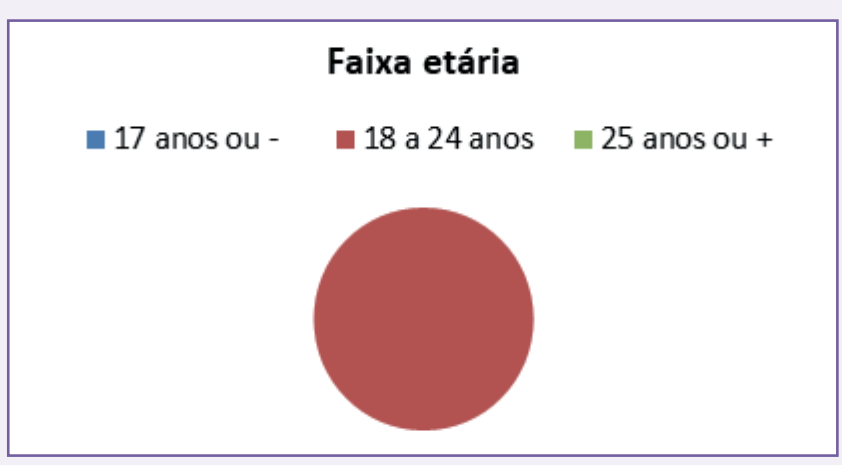

Fonte: Elaborado pela pesquisadora. 
Gráfico 3 - Consumo do Refrigerante Pepsi

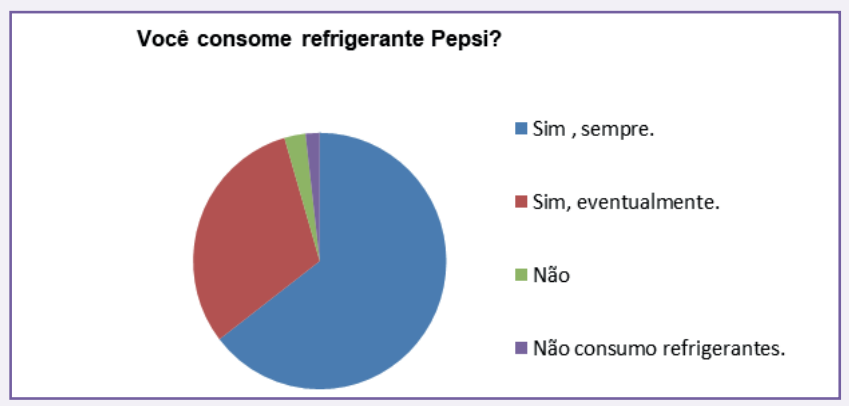

Fonte: Elaborado pela pesquisadora.

Pode-se observar que $100 \%$ dos respondentes estão dentro da faixa etária proposta para esta pesquisa, sendo a maioria deles $(53,6 \%)$ do sexo masculino. Observa-se também que 95,4\% afirmaram serem consumidores do refrigerante Pepsi, sendo que apenas $30,9 \%$ do total consomem eventualmente, ao passo que 64\% responderam que consomem sempre

Gráfico 4 - Lembrança de ação promocional da Pepsi

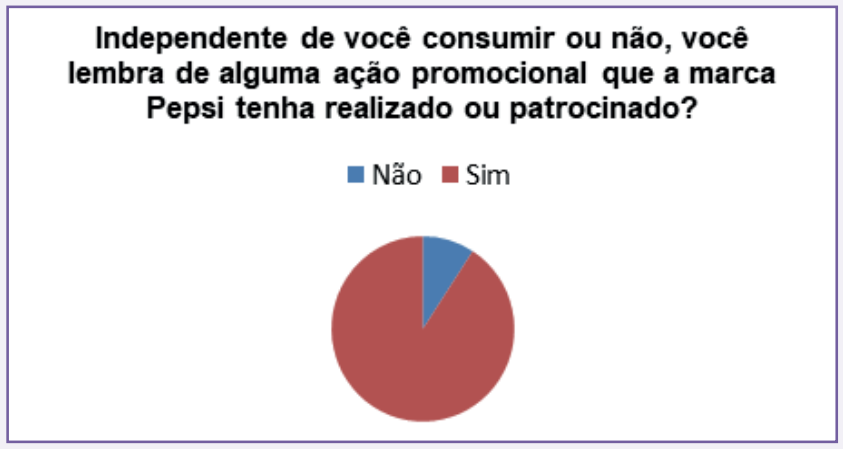

Fonte: Elaborado pela pesquisadora.

Gráfico 5 - Ações promocionais Pepsi mais lembradas

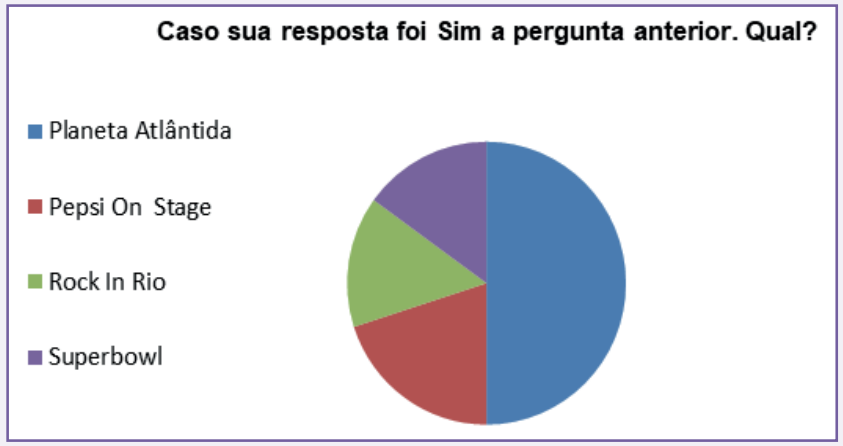

Fonte: Elaborado pela pesquisadora.
Pode-se observar que $91 \%$ dos respondentes se lembraram de alguma ação promocional que a marca tenha realizado ou patrocinado. Dos que responderam afirmativamente a essa pergunta, metade deles se recorda do patrocínio do evento Planeta Atlântida por parte da Pepsi. Com 20\% a casa de eventos Pepsi On Stage foi a segunda ação mais mencionada na pesquisa. E em terceiro lugar entre os eventos patrocinados pela empresa há um empate entre o Rock in Rio e o Super Bowl, ambos mencionados em 15\% das respostas.

Gráfico 6 - Seguem alguma rede social da Pepsi?

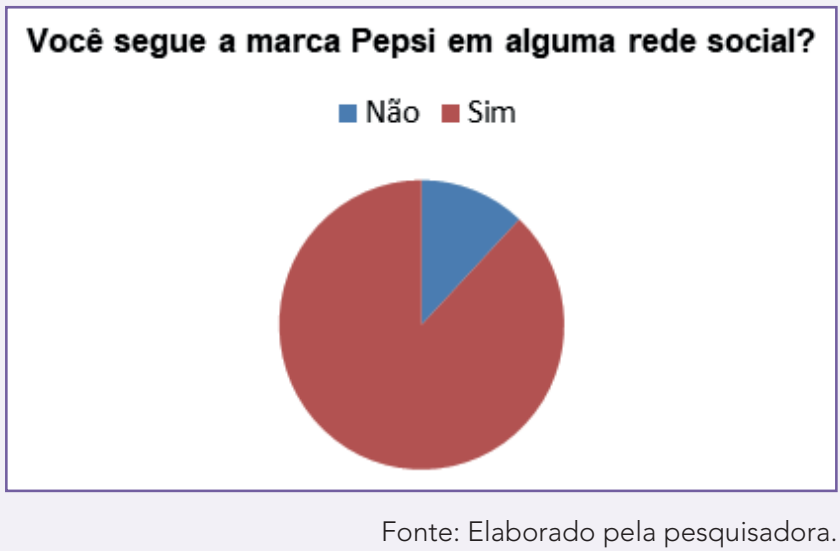

Gráfico 7 - Redes sociais mais seguidas

\section{Caso sua resposta foi "Sim" à pergunta anterior, qual?}

Eacebook $\quad$ Twitter

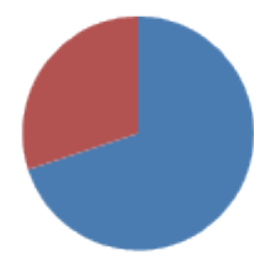

Fonte: Elaborado pela pesquisadora

Percebe-se que $88 \%$ dos respondentes segue a marca Pepsi em alguma rede social, sendo a rede mais seguida o Facebook, com 70\%. Em segundo lugar, nas redes sociais mais seguidas pelos respondentes, encontra-se o Twitter com 30\%. 
Gráfico 8 - Engajamento em ações promocionais da Pepsi

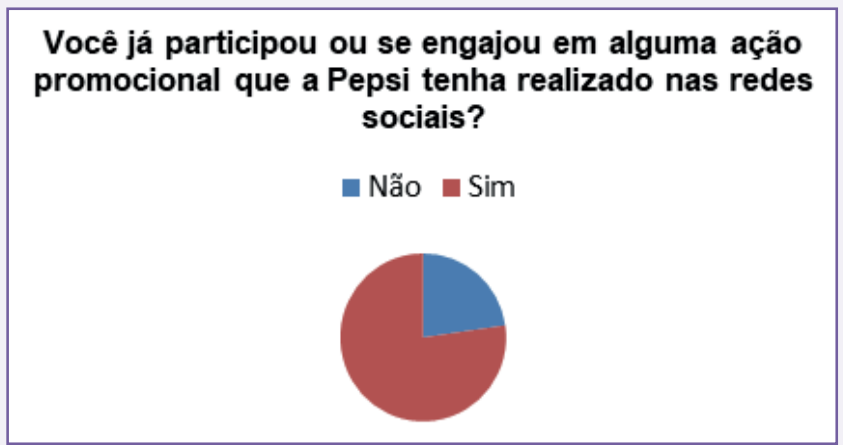

Fonte: Elaborado pela pesquisadora.

Gráfico 9 - Quais ações promocionais?

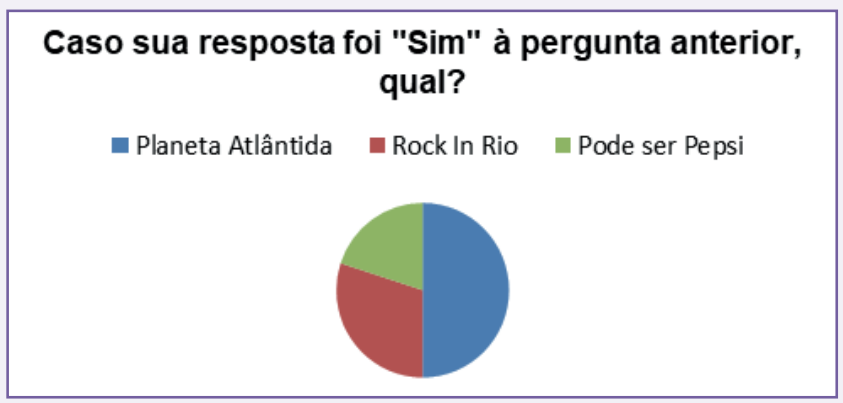

Fonte: Elaborado pela pesquisadora.

Pode-se observar que $77 \%$ dos respondentes já participaram ou se engajaram em alguma ação promocional da marca Pepsi nas redes sociais. Entre os entrevistados, a ação mais lembrada foi o Planeta Atlântida com 62\%, seguido pelo Rock in Rio, com 23\%. O posicionamento "Pode ser Pepsi" ficou com 15\% de lembrança.

Gráfico 10 - Impacto das ações promocionais

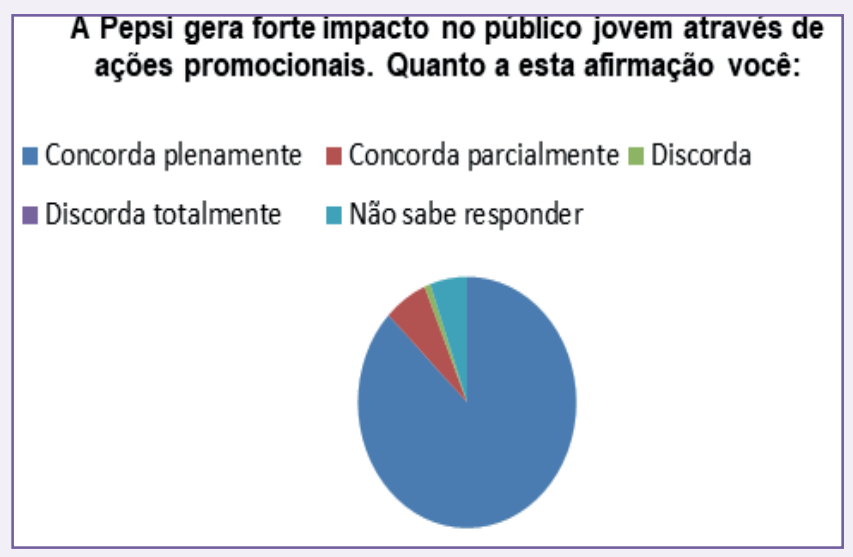

Fonte: Elaborado pela pesquisadora.
Evidencia-se que a maioria dos respondentes concorda que a Pepsi consegue gerar forte impacto no púbico jovem por meio de ações promocionais, sendo que $87 \%$ concordam plenamente e $6 \%$ concordam parcialmente.

Gráfico 11 - Ações promocionais se adaptam a realidade do Rio Grande do Sul?

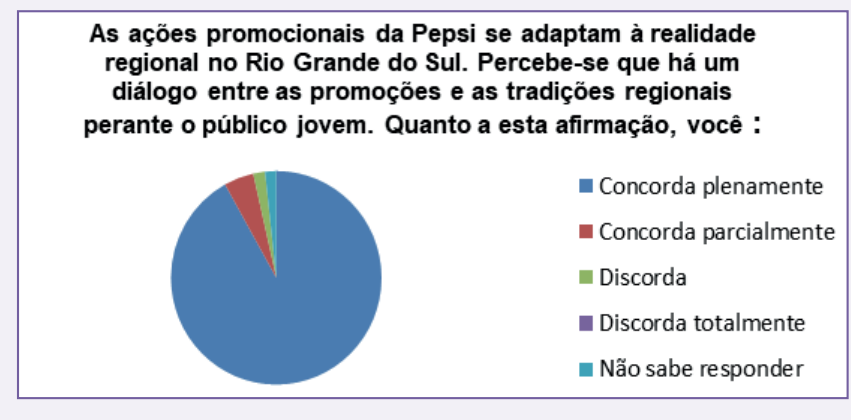

Fonte: Elaborado pela pesquisadora

No gráfico acima, visualiza-se que $95,4 \%$ dos respondentes concordam com a afirmação de que as ações promocionais da marca Pepsi conseguem se adaptar à realidade regional do Rio Grande do Sul, além de perceberem também a existência de diálogo entre as promoções e as tradições regionais perante o público jovem. Dos respondentes, 90,9\% concordam plenamente e $4,5 \%$ concordam parcialmente.

Gráfico 12 - A marca Pepsi consegue despertar paixão perante os consumidores jovens residentes de Porto Alegre?

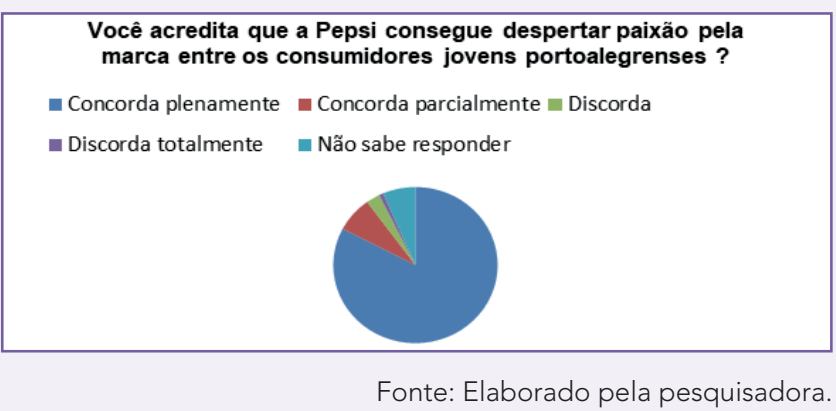

Pode-se observar que $90 \%$ dos respondentes concordam que a Pepsi consegue despertar paixão pela marca perante os consumidores jovens moradores de Porto Alegre. A respeito dessa frase, $83 \%$ concordam plenamente e $7 \%$ concordam parcialmente com ela. 
Gráfico 13 - A marca Pepsi conseguiu maior identificação com o público jovem quando assumiu seu posicionamento "Pode ser Pepsi"

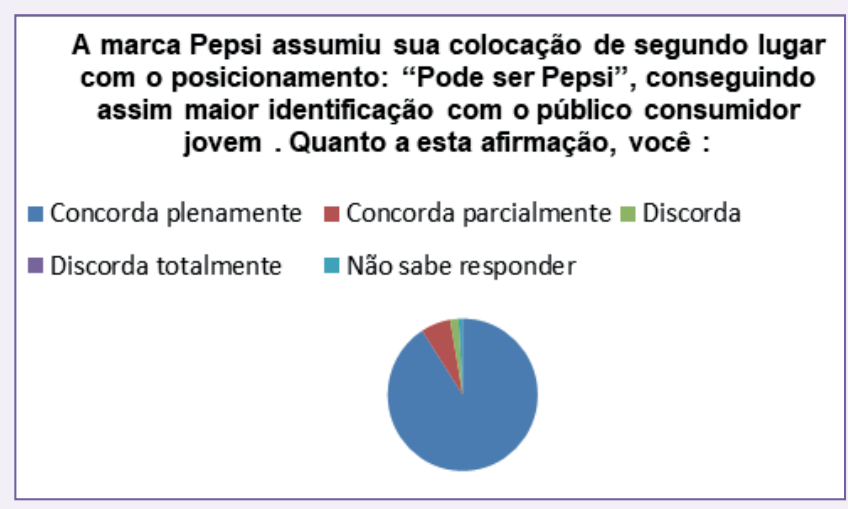

Fonte: Elaborado pela pesquisadora.

Observa-se que $98 \%$ dos respondentes concordam com a ideia de que a Pepsi conseguiu o segundo lugar no mercado com o posicionamento "Pode ser Pepsi", angariando, assim, maior identificação com o público jovem. Do total dos jovens que responderam ao questionário, 91\% concordam plenamente e $7 \%$ concordam parcialmente com essa afirmação.

Gráfico 14 - As ações da marca Pepsi geram incremento no consumo entre os jovens e reforça a lembrança e simpatia com a marca?

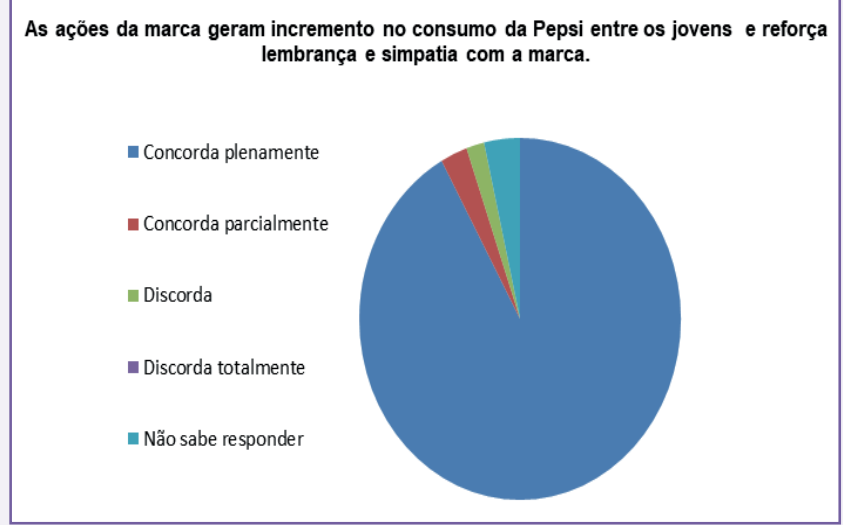

Fonte: Elaborado pela pesquisadora.

Pode-se notar que $94 \%$ dos respondentes concordam com a afirmação de que as ações da Pepsi geram incremento no consumo da marca entre os jovens e reforçam lembranças e simpatia com a marca, sendo que $91 \%$ concordam plenamente e $3 \%$ concordam parcialmente.
Gráfico 15 - O que a marca Pepsi representa para os respondentes

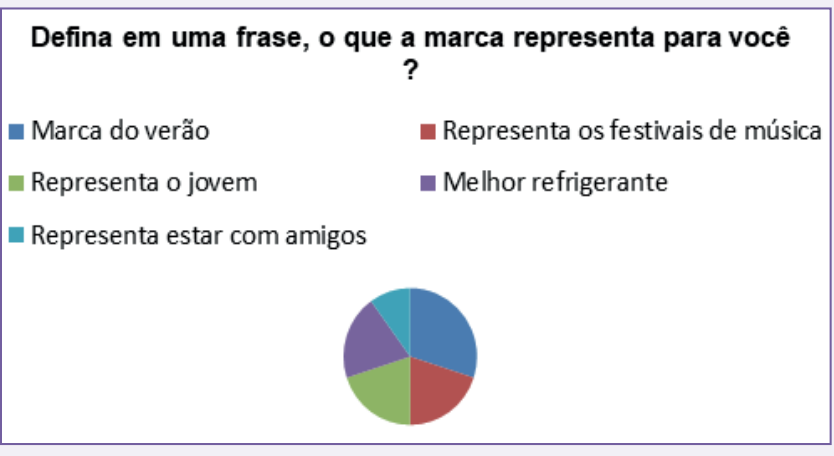

Fonte: Elaborado pela pesquisadora.

Foram 110 respostas diferentes que, por semelhança, foram agrupadas da seguinte forma: "Verão", "Jovem", "Música", "Amigos", "Melhor Refrigerante". Pode-se observar que, de acordo com os respondentes, a marca de refrigerante Pepsi representa varias sensações, situações e momentos. A ideia mais prevalente nas respostas foi, em primeiro lugar com $30 \%$, que a Pepsi representa a marca do verão. Em segundo lugar, houve um empate com 20\% para essas três respostas: a Pepsi "representa o melhor refrigerante"; "representa o jovem"; e "representa os festivais de música". Em quarto lugar, com $10 \%$, encontra-se a posição de que a marca Pepsi "representa estar com amigos".

\section{Nível de percepção em relação à marca}

De acordo com os jovens de 18 a 24 anos, que responderam a pesquisa, observa-se que grande parte é consumidora do refrigerante Pepsi. Foram 110 respondentes, todos na faixa etária de 18 a 24 anos, sendo 46\% feminino e 54\% masculino Por meio do questionário, constatou-se que 95,4\% dos jovens consomem o refrigerante Pepsi. Em relação a essa afirmação, Solomon (2011) escreve que o comportamento de consumo é determinado pelo nível de importância do produto ou marca.

Em relação às ações promocionais, 83\% dos jovens que responderam ao questionário concordaram que a Pepsi consegue impactar os jo- 
vens com suas ações promocionais. Kotler e Keller (2013) explicam que os profissionais de marketing possuem como objetivo obter uma resposta de cunho comportamental do consumidor.

Ao questionar na pesquisa se as ações promocionais da Pepsi se adaptam à realidade regional do Rio Grande do Sul, 95,4\% dos respondentes afirmaram que percebem um diálogo entre as promoções e ações locais. Pigozzo (2013) explica que o marketing global consegue comunicar com a mesma mensagem e a mesma estrutura de produto e marketing nos mais diferentes mercados. Alguns elementos sofrem a necessidade de adaptações com base em costumes locais.

No questionário, $90 \%$ dos jovens concordaram com a afirmação de que a Pepsi consegue despertar paixão pela marca entre os jovens consumidores da região metropolitana. Segundo Oliveira (2015), o brand love se refere a um conceito novo no mercado que ainda está em construção, porém demonstra interesse em longo prazo. A ligação da empresa com o consumidor acontece pelo sentimento de paixão, que ultrapassa a vontade de usar a marca para a lealdade perante a empresa. O maior defensor da marca torna-se o consumidor atuando como um advogado da marca.

Ao abordar no questionário se a Pepsi possui um diferencial na forma de abordar os consumidores jovens e se ela se destaca na concorrência pelos jovens, 92\% dos respondentes concordaram com a afirmação. Para Aaker (2007), é fundamental para o posicionamento de marca ser efetivo conhecer a concorrência. A importância de uma posição estratégica, dentro e fora da empresa, reside na necessidade de declarar a essência do poder de comunicação.

No referente à afirmação de se quando a marca Pepsi assumiu o segundo lugar com o posicionamento "Pode ser Pepsi" teria conseguido maior identificação com o consumidor jovem, 98\% dos pesquisados concordaram com essa asserção. Para Ries e Trout (2009), para obter-se uma posição exclusiva, é necessário fugir do comum, encontrando um conceito fora do produto e voltando o olhar para dentro da mente do público consumidor.

Já na questão sobre se as ações da Pepsi geram incremento no consumo dos produtos entre os jovens e se reforçam a lembrança e a simpatia para com a marca, 94\% dos entrevistados responderam sim a tal afirmação. Kotler e Keller (2013) explicam que o branding serve como o meio de distinguir produtos de uma empresa em relação a outros. Possui a função de elaborar estruturas a fim de auxiliar o público consumidor a organizar o conhecimento em relação aos produtos, com finalidade de tomar a decisão mais objetiva, gerando valor para a empresa.

Quando questionado na pesquisa o que a marca significaria para os jovens, foram coletadas 110 respostas diferentes, que foram agrupadas nas categorias "Verão", "Jovem", "Música", "Amigos" e "Melhor refrigerante". De acordo com os jovens entrevistados, a marca de refrigerante representa várias sensações, situações e momentos. Entre as menções dos entrevistados, em primeiro lugar, com 30\% das respostas, esteve a ideia de que a Pepsi representa a marca do verão. Já na segunda colocação, houve um empate de 20\% para as seguintes respostas: "a Pepsi representa o melhor refrigerante"; "representa o jovem"; e "representa os festivais de música". Para 10\% dos jovens respondentes, a marca Pepsi representa estar com amigos

De acordo com os atributos relatados pelos jovens que responderam à pesquisa, percebe-se que a Pepsi possui perante o público jovem a personalidade da marca. Solomon (2011) explica que a personalidade da marca é o conjunto de características que os consumidores agregam e valorizam ao produto como se fosse uma pessoa. A personalidade da marca também está associada com o posicionamento.

\section{Nível de engajamento com a marca}

No questionário, 88\% dos jovens pesquisados afirmaram que seguem a Pepsi em alguma rede social. O segundo questionamento foi qual rede social. O resultado mensurou que, dos que seguem a Pepsi, 70\% o fazem pelo Facebook e 30\% pelo Twitter. Percebe-se, assim, a interação dos jovens com a marca no meio virtual. Os autores Kotler, Kartajaya e Setiawan (2010) explicam que 
a tecnologia da informação está inserida no mercado e é considerada a nova onda da tecnologia, abrangendo a conectividade e a interação entre pessoas e grupos. As pessoas criam e consomem notícias, pensamentos e diversão.

Quando abordado no questionário se os jovens já se engajaram em alguma ação da Pepsi nas redes sociais, a maioria (77\%) afirmou que sim. As ações mais citadas foram ações promocionais referentes aos eventos Planeta Atlântida, com $62 \%$ das respostas, seguido por Pode ser Pepsi, com $15 \%$, e Rock in Rio, com $23 \%$. Nota-se, assim, um engajamento com a marca nas redes sociais. Os autores Kotler, Kartajaya e Setiawan (2010) explicam que a nova forma de inovação pode ser considerada a colaboração, podendo se tornar uma tendência. $O$ consumidor assume a função de profissionais de marketing, adaptando um produto ou serviço com base no seu estilo de vida pessoal

\section{Participação dos jovens em eventos da Pepsi}

Nota-se, no questionário, o engajamento dos jovens nos eventos da marca. As festas fazem parte das relações sociais como um modo de interação. Partindo disso, os profissionais de marketing elaboram estratégias para fixar as marcas na mente dos consumidores. Kotler e Keller (2006) explicam que, pelo fato de o marketing abranger identificações e satisfações das necessidades humanas e sociais, é escolhido o mercado alvo para atingir e realizar a capacitação e fidelização por meio da comunicação.

De acordo com a pesquisa, 91\% dos respondentes afirmaram lembrar-se de ações promocionais que a Pepsi realizou ou patrocinou. As ações citadas mais lembradas foram Planeta Atlântida, com 50\% das respostas, Pepsi On Stage com $20 \%$, Rock in Rio com 15\% e Super Bowl também com 15\%. Sabe-se que o evento Planeta Atlântida, ocorre em âmbito regional ,no Rio Grande do Sul , e é patrocinado pela Pepsi. O Pepsi On Stage é uma casa de shows da própria marca. Rock in Rio é um festival de música, um evento internacional que ocorre no Brasil. Já o Super Bowl é um even- to esportivo patrocinado pela Pepsi, que ocorre nos EUA. Os autores Kotler e Armstrong (2015) explicam que o marketing atende o público com a finalidade de manter os clientes, apresentando satisfação, além de atrair novos consumidores, prometendo-lhes valor.

Quando questionado na pesquisa se os respondentes já se engajaram em alguma ação promocional que a marca tenha realizado nas redes sociais, 77\% afirmaram que sim. Entre as ações promocionais citadas, $85 \%$ foram a eventos: o Planeta Altântida teve $62 \%$ das menções enquanto que o Rock in Rio obteve 23\%. Os autores Kotler, Kartjaya e Setianwan (2010) explicam que a participação pode ser vista como um novo meio de inovação. De acordo com a disposição em crescer, os profissionais de marketing não contam mais do poder absoluto sobre suas marcas em virtude de competir com o controle coletivo dos consumidores. O público assume a função dos profissionais, uma vez que os consumidores estão ativamente conectados uns aos outros.

Na pergunta a respeito do que a marca representa para os pesquisados, optou-se por uma questão aberta. As respostas citadas foram muitas, sendo posteriormente agrupadas por semeIhança. Entre as pesquisados, $20 \%$ associaram a marca aos festivais de música, o que salienta a importância da Pepsi na participação em eventos. Nesse sentido, os autores Para Solomon (2011), a personalidade da marca é um composto de particularidades que o público agrega valor ao produto como se fosse uma pessoa.

\section{Conclusão}

Este estudo teve como propósito analisar o posicionamento da marca e enfocar como as suas ações promocionais influenciam o comportamento do consumidor. A percepção dos jovens residentes na Região Metropolitana de Porto Alegre em relação à marca. $\bigcirc$ objeto de análise, o refrigerante Pepsi, é uma marca global que utiliza uma comunicação que escapa do convencional. O estudo indica, a partir das ações promocionais e dos eventos patrocinados pela Pepsi, que os jovens têm a percepção de que a marca agrega ao 
próprio nome uma personalidade.

A pesquisa se caracterizou como descritiva e quantitativa, analisando respostas de jovens de 18 a 24 anos de idade, consumidores ou não da Pepsi. A proposta foi buscar um entendimento sobre o perfil do público-alvo e como as ações da marca impactam as vidas dos consumidores. Realizou-se pesquisa bibliográfica e documental, utilizando-se como instrumento de pesquisa o questionário online. Para a análise dos dados coletados, usou-se a análise de conteúdo categorial, definindo os dados em três segmentos. A pergunta de pesquisa deste estudo foi: qual a percepção dos jovens em relação à Pepsi, a partir do posicionamento da marca?

A partir do que foi exposto no referencial teórico deste estudo, junto com as análises, defende-se que a pergunta foi respondida, pois a percepção dos jovens em relação à marca é positiva. A Pepsi consegue se posicionar, comunicar com o público jovem a partir de suas ações promocionais e participações em eventos. O objetivo geral do trabalho foi verificar a percepção dos jovens em relação à Pepsi, a partir do posicionamento da marca. E os objetivos específicos foram analisar quais as ações da Pepsi que impactaram e geraram mais engajamento dos jovens moradores da Região Metropolitana de Porto Alegre com a marca e avaliar o nível de empatia da marca Pepsi com o público jovem morador da Região Metropolitana.

A partir do que foi observado e explorado nas análises da pesquisa, percebeu-se que os objetivos foram positivos e alcançados. Foram analisadas quais ações que a Pepsi realizou que impacta- ram e geraram engajamento dos jovens. Foram citadas as ações promocionais dos festivais de música Planeta Atlântida e do Rock in Rio, além do Super Bowl. Foi fundamental a compreensão dos fatores analisados a interpretação dos resultados obtida junto às categorias, pois serviu para reforçar a percepção em relação à marca, além do engajamento com a marca, e também participação dos jovens em eventos da Pepsi. Mesmo quem não consome o refrigerante, tem a percepção de que a marca é diferenciada. A Pepsi consegue impactar os jovens que passaram além dos produtos vendidos.

A importância da pesquisa para o mercado reflete na importância das marcas conhecerem bem o seu mercado com o propósito de conseguir comunicar e conversar melhor com o público que deseja atingir para obter êxito em sua jornada. A limitação da pesquisa dá-se pelo fato de ser uma amostra circunscrita. Para obter maior profundidade, seria indicado ampliar o número de participantes com jovens de todos os lugares do estado do Rio Grande do Sul e não somente de Porto Alegre e Região Metropolitana. A importância da pesquisa para a pesquisadora se reflete na relevância das marcas conhecerem melhor o público a quem desejam. Lembrando também que a Pepsi foi líder no estado por muitos anos e estar presente em tantos eventos e festivais que conversam com o jovem. Este estudo não se esgota. O trabalho pode servir de inspiração para novas pesquisas que envolvam percepções e posicionamentos de marca. Para isso, podem ser realizados estudos com outras marcas de refrigerante que buscam seu diferencial no mercado. 


\section{Referências}

AAKER, David A. Construindo Marcas Fortes. Tradução: Maria Lúcia Badejo Porto Alegre: Bookman, 2007. ABIR. Dados sobre consumo de bebidas. Disponível em: <http://abir.org.br/o-setor/dados/>. Acesso em: 22 mar. 2017.

CATEORA, Phillip; GRAHAM, John. Marketing Internacional. 13. ed. Rio de Janeiro: S.A. LTC - Livros Técnicos e Científicos, 2009.

EXAME. Fatos sobre o comportamento dos jovens brasileiros. Disponível em: <http://exame.abril.com.br/ marketing/10-fatos-sobre-o-comportamento-dos-jovens-brasileiros/>. Acesso em: 15 mar. 2017.

G1. Estudo aponta que 30 dos jovens do Brasil tomam refrigerante diariamente. Disponível em: <http:// g1.globo.com/bemestar/noticia/2016/04/estudo-aponta-que-30-dos-jovens-do-brasil-tomam-refrigerantediariamente.html>. Acesso em: 17 mar. 2017.

KOTLER, P.; ARMSTRONG, G. Princípios de Marketing. 15. ed. São Paulo: Pearson Education do Brasil, 2015.

KOTTLER, P.; KELLER, L. Administração de Marketing. 14. ed. São Paulo: Pearson Education do Brasil, 2013.

KOTLER, Philip; KARTAJAYA, H.; SETIAWAN, I. Marketing 3.0: as forcas que estão definindo o marketing no ser humano. Rio de Janeiro: Elsevier, 2010.

LEVINE, D. M. Estatística: teoria e aplicações. 5. ed. Rio de Janeiro: TLC, 2008.

MALHOTRA, Naresh. Introdução à Pesquisa de Marketing. São Paulo: Pearson Pratice Hall, 2005.

MUNDO DAS MARCAS. Pepsi-Cola. Disponível em: < http://mundodasmarcas.blogspot.com.br/2006/05/pepsicola-next-generation.html >. Acesso em: 15 mar. 2017.

NIELSEN: Fatores essenciais que movem o mercado de bebidas. Disponível em: < http://www.nielsen.com/br/ pt/insights/news/2016/4-fatores-essenciais-que-movem-o-mercado-de-bebidas.html>. Acesso em: 16 mar. 2017.

PIGOZZO, Ana. Marketing Internacional. Curitiba: Intersaberes, 2013.

RIES, Al; TROUT, Jack. Posicionamento: a batalha por sua mente. São Paulo: M. Books, 2009.

SOLOMON, Michael. Comportamento do Consumidor: comprando, possuindo e sendo. 9. ed. Porto Alegre: Bookman, 2011. 